\section{Influenza according to Hoyle}

SIR-Perhaps we should examine more closely the possibility that a primary extraneous source of influenza and other viruses is terrestrial ocean water, with or without polar ice and other solid matter, carried up into terrestrial or solar orbits, including pseudo-cometary orbits, by grazing collisions of large celestial bodies impinging upon the Earth. In general, the type of solar orbit would be a stronger function of the trajectory of the grazing body than that of the Earth, but the case of major interest would be a trajectory in the Earth's orbital plane.

The entrained water would be rapidly frozen in the near-vacuum and its viruses might well survive storage times of the order of $10^{8}$ years, as neither mainstream solar radiation nor solar flares might be expected to be a strong agent in their destruction. Comets survive. If the Earth crossed the wake of the debris, however, both ambient atmospheric conditions and special conditions brought about by solarflare activity might well play a part in enhancing the probability of nondestructive release of the viruses. Because the latter would most probably be prehuman, the human race would have had no opportunity to develop resistance. It would not be necessary to postulate an extraterrestrial origin for the viruses.

D. G. ANDREWS

\section{Department of Chemical Engineering} and Applied Chemistry,

University of Toronto,

Toronto,

Canada M5S $1 A 4$

SIR - In their letter repeating the idea of a connection between sunspot maxima and influenza pandemics, Hoyle and Wickramasinghe ${ }^{1}$ have correctly pointed out that "past experience has shown that false correlations of phenomena with the sunspot cycle may look good over a few cycles but go seriously adrift after an appreciable number of cycles".

The graph below shows sunspot cycles and influenza outbreaks using Hoyle's own list for pandemics and for sunspot maxima (except for 1767 which was not a maximum year), together with the annual sunspot numbers published by Waldmeier ${ }^{2}$. It seems obvious that the occurrence of pandemics is fairly well distributed over all phases of the solar cycle - contrary to what the authors want to imply.

Furthermore, with the exception of the pandemic of 1889 (coinciding with a sunspot minimum), it is doubtful which of the historic epidemics listed by Beveridge belong to the category of pandemics. For comparison, Creighton's History of Epidemics in Britain ${ }^{3}$ looks rather different: $1562,1580-82,1665,1733,1743,1782$, $1833,1847,1889$. Among these years, the phase of the sunspot cycle before 1700 is uncertain: however, the years 1733, 1743, 1782,1833 and 1889 all happen to be years of sunspot minima ( 3 cases) or one year before minimum ( 2 cases).
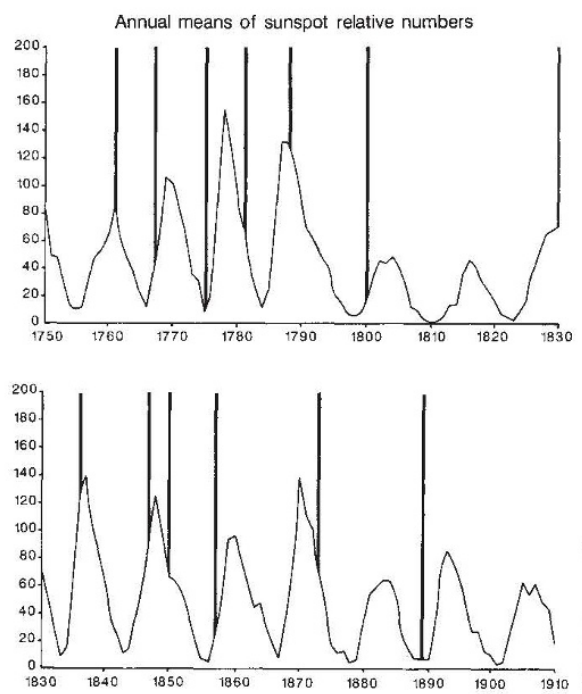

As an astronomer, I refrain from strengthening my point by biological arguments. These were recently published by Henderson et al. ${ }^{\dagger}$. More information on the history of epidemics and pandemics may be found in Basic and Applied Influenza Research ${ }^{5}$. \section{Kiepenheuer-Institut für SOnnenphysik,} Schöneckstrasse. 6 , D-7800 Freiburg i.Br., FRG

1. Hoyle, F. \& Wickramasinghe, N.C. Nature 343, 304 (1990)

2. Waldmeier, M. The Sunspot Activity in the Years 1610 1960 (Schulthess, Zurich, 1961).

3. Creighton, C. A History of Epidemics in Britain, Vois $1 \& 2$ (Cambridge University Press 1891, 1894); 2nd Edn (Frank Cass, London and Barnes \& Noble, New York 1965).

4. Henderson, I.M., Hendy, M.D. \& Penny, D. J. theor. Biol. 140, 289-303 (1989)

5. Beare, A.S. (ed.), Basic and Applied influenza Research. CRC, Boca Raton, 1982)

\section{No carbon tax}

SIR - I am disturbed by the suggestion of a so-called carbon tax on fuels, for several reasons.

(1) When taxes are introduced for nonfiscal reasons, they end up benefiting only the Exchequer, with the original reason long forgotten. The road fund is perhaps Britain's best known example.

(2) Carbon dioxide is not a pollutant, but an essential ingredient of the Earth's atmosphere. In geological time, the amount of carbon dioxide in the atmosphere has varied very widely, and although the reasons for the widest variation are known, the details are mysterious and complex. There may be natural influences of which we know nothing that are either increasing or decreasing the atmospheric content. An increase in carbon dioxide may even be beneficial by stimulating plant growth.

(3) The reason advanced for taking steps to lower the carbon dioxide content, or at least to slow its rate of increase, is the so-called greenhouse effect. It is not known whether this effect is occurring, and, if it is, whether this would be bad or good. The tendency of the climate over the next period of time may be towards another ice age, in which case the greenhouse effect might be of the greatest value to us.

(4) The proposed carbon tax would be a great burden to manufacturers, public and private transport and to householders wishing to use any form of power in the house. Indeed, it is the proclaimed object of the tax to cause a change in the power consumption habits of the world.

Habits are not so easily changed, and this proposal is in the style of many directives that have proved unsuccessful during the past century. A more likely result is that habits would continue largely unchanged, and that the extra burden would end up in inflation, which is more likely to cause damage to the world and its economy than is carbon dioxide.

Finally, I wonder why we are so convinced that the present state of the world is the best possible one. In the past, carbon dioxide concentration, temperature and sea level have all varied far more widely than are envisaged in any of the projections made for the greenhouse effect. The result of all these changes has been the world we know, which is apparently regarded as satisfactory. Why then should any changes be regarded as necessarily deleterious?

12 Avenue Road

DAVID A. H. TAYLOR Scarborough,

Yorkshire, Y012 5JX, UK

\section{Whistle-blowing}

SIR-You are correct in pointing out (Nature 343, 396) that "whistle-blowing is always a dangerous trade, the more so when directed against more powerful colleagues", and we share your regret that "Nature is not in a position to offer protection of any kind to those exposed". Should matters be allowed to rest there? It is hardly likely that such problems are confined to the Indian subcontinent. The Council for Science and Society is gathering material on this topic; we would welcome accounts of particular incidents (which would be treated in strictest confidence) and also suggestions for means of protecting whistle-blowers in the future.

JEROME R. RAVETZ (Chairman)

BERNARD DIXON (Vice-Chairman)

The Council for Science and Society,

3/4 St Andrews Hill,

London EC4V 5BY, UK 